\title{
Uncovering prevalence of pangolin consumption using a technique for investigating sensitive behaviour
}

\author{
Alegria Olmedo, Diogo Veríssimo, E. J. Milner-Gulland, Amy Hinsley \\ Huong Thi Thu Dao and Daniel W.S. Challender
}

\begin{abstract}
Pangolins have been exploited throughout history but evidence points to population declines across parts of their ranges since the 196os, especially in Asia. This is the result of overexploitation for local use and international trade and trafficking of their derivatives. The prevalence of the consumption of pangolin products has been estimated for different localities in Viet Nam but, considering that national legislation prohibits the purchase of pangolin products, previous research has not accounted for the potential for biased responses. In this study, we treat pangolin consumption as a sensitive behaviour and estimate consumption prevalence of pangolin meat, scales and wine (a whole pangolin or pangolin parts or fluids soaked or mixed in rice wine) in Ho Chi Minh City using a specialized questioning method, the unmatched count technique. We also characterize the demographics of consumers. Our results suggest there is active consumption of all three pangolin products, with a best-estimate prevalence of $7 \%$ of a representative sample of Ho Chi Minh City residents for pangolin meat, $10 \%$ for scales and $6 \%$ for wine. Our prevalence estimates exceed estimates from direct questions, providing evidence for the sensitivity of pangolin consumption. We compared our analysis of consumer characteristics with existing profiles of pangolin consumers and found substantial differences, suggesting that consumption occurs among broader demographic groups than previously described. Our findings suggest that efforts to reduce demand for pangolin consumption in Viet Nam should focus on a broader range of consumers than previously identified.
\end{abstract}

Keywords Illegal wildlife trade, pangolin, sensitive behaviour, specialized questioning methods, unmatched count technique, Viet Nam

ALEGRIA OLMEDO* + (Corresponding author, (D) orcid.org/0000-0001-7256-8875), Diogo Verissimo† Amy Hinsley and Daniel W.S. Challender $\dagger$ Department of Zoology, University of Oxford, Zoology Research and Administration Building, 11a Mansfield Road, Oxford, OX1 3SZ, UK

E-mail alegria.olmedocastro@zoo.ox.ac.uk

Huong Thi Thu Dao Save Vietnam's Wildlife, Cuc Phuong, Viet Nam

${ }^{*}$ Also at: People for Pangolins, London, UK

$\dagger$ Also at: IUCN SSC Pangolin Specialist Group, London, UK

¥Also at: San Diego Zoo Global, San Diego, USA

Received 15 May 2020. Revision requested 17 June 2020.

Accepted 9 October 2020. First published online 7 April 2021.
Supplementary material for this article is available at doi.org/10.1017/Soo30605320001040

\section{Introduction}

$\mathrm{O}$ verexploitation is a major threat to many species, affecting plants and animals used for various purposes, including medicine, food and ornaments, ultimately threatening ecosystem processes and functions (Broad et al., 2003; Maxwell et al., 2016). Reducing consumer demand for unsustainably or illegally traded species has been identified as a priority, recognizing that law enforcement is by itself inadequate to control trade (Challender \& MacMillan, 2014; CITES, 2016; Hanoi Statement, 2016). Efforts to reduce demand for wildlife products have increased substantially since 2010 (Veríssimo \& Wan, 2018). However, these efforts do not always follow best practice, as they are often not based on an understanding of consumers. Best practice includes conducting in-depth research prior to intervening to understand consumer motivations around the use of illegally traded products and to discern the underlying drivers of consumption that must be addressed, the specific behaviours to be influenced, and the individuals performing them (Greenfield \& Veríssimo, 2018; Olmedo et al., 2018). Such in-depth research also facilitates identification of the most appropriate and influential messages and messengers to catalyse behaviour change for a particular consumer group (Veríssimo et al., 2020).

Pangolins are legally protected in most range states (IUCN SSC Pangolin Specialist Group, 2016), and all eight species are included in Appendix I of CITES, meaning international commercial trade in wild-caught pangolins and their products is prohibited. However, estimates suggest the equivalent of c. 715,000 pangolins were trafficked globally between 2010 and July 2019 (Challender et al., 2020). Evidence also indicates that overexploitation of pangolins since 2000 has led to severe population declines, especially in parts of East and South-east Asia (Newton et al., 2008; Chong et al., 2020; Wu et al., 2020). In Viet Nam, enforcement challenges, combined with prevailing demand and increasing wealth, particularly in urban centres with high per capita incomes, means that more people are able to purchase expensive and aspirational items, including pangolin products (Nijman, 2009; Challender et al., 2019). Available 
data suggest that large quantities of pangolin scales and whole animals are trafficked to Viet Nam each year from other countries in South-east Asia, such as Malaysia, and from Africa (Heinrich et al., 2017). There are two pangolin species native to Viet Nam, the Sunda pangolin Manis javanica and Chinese pangolin Manis pentadactyla, both of which are probably consumed or otherwise used in the country (Chong et al., 2020; Wu et al., 2020).

The concept of sensitivity is relevant for research on the consumption of illegally traded wildlife. Tourangeau et al. (2000) discussed three aspects of this concept: (1) intrusive: raising the topic is considered inappropriate and the questions can offend respondents; (2) threat of disclosure: respondents worry about the potential consequences of answering sensitive questions honestly, regardless of assurances that information provided will remain confidential; and (3) social desirability: respondents modify their answers to reflect what is deemed socially desirable and underreport activities that are not. The third meaning assumes clear social norms exist regarding a given behaviour (Tourangeau \& Yan, 2007).

Despite the importance of recognizing when designing and interpreting research on the illegal wildlife trade that the purchase and consumption of pangolins and their derivatives is likely to be sensitive, past research on pangolin consumption in Viet Nam has not addressed this potential bias. However, in their study to characterize demand for wild meat in Hue, Viet Nam, Sandalj et al. (2016) did recognize the possibility of respondents underreporting consumption because of its illegality. There have been several mass media campaigns since 2015 highlighting the illegality of purchasing and consuming pangolin products (ENV, 2017; WildAid, 2019). Consequently, consumers may now be less willing to disclose such behaviours because of fear of legal consequences and perceived shifts in social norms (Thomas et al., 2017).

With respect to the first aspect of sensitivity, enquiring about an illegal behaviour could be seen as intrusive and discussing it could offend respondents, potentially implying they may have carried it out, particularly if the enquirer is unknown to them. With respect to the second concept, disclosing the purchase or consumption of pangolin products would confirm the respondent had broken the law and cause concern that answers would be shared with authorities, leading to legal consequences. However, because of the lack of effective law enforcement in Viet Nam (UNODC, 2015) there is probably little or limited perceived risk in engaging in these activities. With respect to the third concept, we can assume that performing an illegal behaviour is socially undesirable, in which case those who have consumed pangolins would be inclined to deny it. Purchasing specific wildlife products can, however, be a way to convey one's social status in Viet Nam (Shairp et al., 2016), and consuming pangolin products could therefore be a socially desirable behaviour and respondents may thus claim they have consumed them when they have not.

All these considerations suggest that respondents could under- or over-report consumption, and therefore in this research we considered consumption of pangolin products to be a sensitive behaviour. Our aim was to explore the prevalence of consumption of three pangolin products known to be available in Ho Chi Minh City, Viet Nam: scales, meat and wine (a whole pangolin or pangolin parts or fluids soaked or mixed in rice wine; Do et al., 2011; WildAid, 2016; USAID, 2018). We used methods appropriate for sensitive behaviours, to mitigate response bias. We also aimed to characterize the profiles of consumers of the three products. To our knowledge, this is the first study that has considered the risk of bias when investigating consumption of pangolin derivatives and products.

\section{Study area}

We selected Ho Chi Minh City because it has the highest gross domestic product per capita in Viet Nam (General Statistics Office, 2016), suggesting residents have higher disposable income than elsewhere in the country and may therefore potentially be able to purchase aspirational products such as pangolin derivatives and products.

\section{Methods}

\section{Sampling}

We calculated the sample size necessary to achieve power to detect consumption of pangolin products, based on a random representative sample of the Ho Chi Minh City population. Ho Chi Minh City had 8,441,903 inhabitants in 2016 (Ho Chi Minh City Statistical Office, 2016). Using a confidence level of $95 \%$, and a confidence interval of $3 \%$, our target sample size was 1,067 but we aimed to acquire 1,200 respondents to account for incomplete responses. Respondents were individuals who had resided in the city for at least the previous 12 months (at the time of the survey), and were $\geq 18$ years old.

We used stratified sampling to select target districts in Ho Chi Minh City. We compared urban and rural districts, as defined by the Vietnamese government, with respect to key variables that we hypothesized could influence pangolin consumption. We hypothesized that these would include population density and income but, as data on income per district was not available, we used the number of education and health service facilities in each district as a proxy for income per capita (Falkingham \& Namazie, 2002). We hypothesized that income could influence the consumption of pangolin products, which have been described as expensive (WildAid, 2016; USAID, 2018), and thus wanted to 
observe whether consumption varied in areas of different per capita income. We also hypothesized that population density could influence consumption because a greater aggregation of people could result in higher commercial activity and thus greater availability of pangolin products. There were differences between rural and urban districts: population density and monthly average income per capita were substantially higher in urban districts (median 27,005 people per $\mathrm{km}^{2}$ vs 1,553 people per $\mathrm{km}^{2}$ in rural districts; income in urban districts VND 5,118,400, c. USD 220, vs income in rural districts VND 3,578,400, c. USD 150). Thus, rural and urban districts were treated separately in the sampling process. Districts with higher or lower values than the norm for their category (Ho Chi Minh City Statistical Office, 2016) were classified as outliers and excluded from sampling. Based on the constraints of field work (i.e. time and resources) and the target sample size, we randomly selected six districts from the final list of representative districts: four urban and two rural (Fig. 1). The sample size in each district followed stratified proportional random sampling (Newing et al., 2010) and, as c. $80 \%$ of people live in urban districts and c. $20 \%$ in rural districts, we apportioned the sample sizes in the urban and rural districts accordingly.

We used a questionnaire and intercept surveys to collect data on consumption at the individual level (Newing et al., 2010). We used systematic sampling, in which research assistants approached every second person. We piloted the questionnaire in October 2018 with 128 respondents, which also enabled identification of areas where there was sufficient foot traffic for the intercept surveys. The pilot survey informed questionnaire design through testing of indirect and direct questions, which helped with the selection of appropriate multiple-choice answer options. To mitigate non-response and social desirability biases the surveys were conducted on tablets and were self-administered. This has been found to increase the likelihood of respondents reporting on sensitive information, although it can also result in incomplete questionnaires (Tourangeau \& Yan, 2007). Self-administered questionnaires have also been found to reduce over-reporting of socially desirable behaviours (Presser \& Stinson, 1998). We collected data with the help of eight graduate research assistants, who were trained in surveying techniques beforehand, during 30 October-29 November 2018. We visited locations in the morning, afternoon and evening on weekdays and weekends, to ensure a diverse range of respondents were encountered. We collected basic demographic data from respondents (district of residence, age, gender, education, income, marital status and profession).

\section{Specialized questioning approach}

We chose the unmatched count technique as our method to obtain an estimate of prevalence of pangolin consumption.

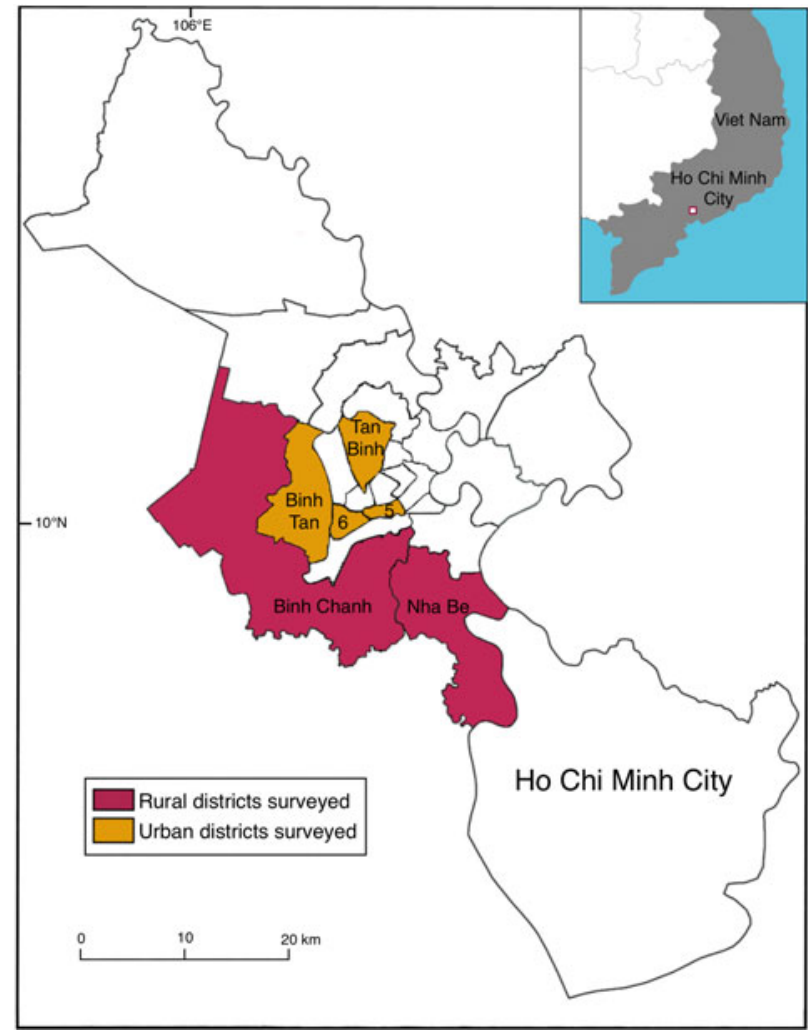

FIG. 1 The districts of Ho Chi Minh City, Viet Nam, indicating the urban and rural districts where surveys were carried out.

This technique is increasingly being used in conservation (St. John et al., 2010; Nuno et al., 2013; Davis et al., 2019a), as it is more effective than direct questions in estimating prevalence of a sensitive behaviour (Tsuchiya et al., 2007). In addition, respondents do not have to randomize the responses themselves. The simplicity of the technique can also avoid confusion among respondents regarding how the method provides privacy (Hubbard et al., 1989; Imai, 2011).

The unmatched count technique, also known as the item count technique or list experiment, assigns respondents to either a treatment or a control group. Each group is presented with a list; the control group is given a list of nonsensitive items and the treatment group receives the same list plus a sensitive item of interest. Both groups are requested to state the number of the items in the list that apply to them (e.g. behaviours they have performed, products they have consumed). The prevalence of the sensitive item is then calculated by conducting a difference of means calculation between the answers of the two groups (Hinsley et al., 2019). We used three unmatched count technique questions to enquire about consumption of pangolin meat, scales and wine in the previous 12 months. Each respondent was randomly allocated (via the randomization feature of the tablets) to either the control or treatment group of each question. Both groups were presented with four non-sensitive items related to either food (for pangolin meat), medicine 
(for pangolin scales) or beverages (for pangolin wine). Each respondent was asked to state the number of products (up to four for the control group and five for the treatment group) they had consumed in the previous 12 months. The treatment group was presented with a list in which the pangolin product was included among non-sensitive items and the control group was presented with the list of non-sensitive items only (Supplementary Material 1; Nuno \& St. John, 2015).

Non-sensitive items in each list were related to the sensitive item so as not to arouse suspicion about the presence of the pangolin product, following Tsuchiya et al. (2007). To avoid ceiling and floor effects, in which respondents have consumed either all or none of the items on the list (Glynn, 2013), each unmatched count technique list included non-sensitive products with high, medium and low prevalence of consumption. Control non-sensitive items were identified in October 2018 by approaching residents in public locations of all target districts and discussing perceptions on the prevalence of consumption of appropriate products.

\section{Direct questions}

Direct questions on the consumption of pangolin products were included at the end of the questionnaire. This was to allow comparison between direct and indirect questioning techniques, thereby giving insights on the degree of sensitivity of pangolin product consumption and providing a minimum estimate of consumption prevalence (Nuno \& St. John, 2015). We designed these as multiple answer questions in which respondents could select more than one answer (where applicable), including an 'other' option.

\section{Analysis}

We analysed the data in $R$ 3.5.2 (R Core Team, 2019) using the list package (Blair et al., 2020). We first used the ict test to check for design effects in the unmatched count technique questions; i.e. whether the presence of the sensitive item in the treatment question affected respondents' answers to the control items (no design effect was detected). We also conducted combined list estimator analysis, which combines the unmatched count technique and direct question responses to obtain a more robust estimate. The combined analysis conducts two design tests: placebo test one and two. Placebo test one conducts three tests: for false positive confessions, for whether individuals who directly admit to performing the sensitive behaviour also state that the behaviour applies to them in their answer to the unmatched count technique question, and for design effects. Placebo test two examines whether the answer given by individuals in the treatment group is affected by seeing the sensitive item in the unmatched count test list. No design effect was found from either placebo test for pangolin meat (test one: $\mathrm{P}=0.75$; test two: $\mathrm{P}=0.35$ ) or wine (test one: $\mathrm{P}=0.35$; test two: $\mathrm{P}=0.41$; Aronow et al., 2015). There were not enough positive responses to the direct question on pangolin scale consumption and therefore we could not conduct the placebo tests for this product (Aronow et al., 2015). We therefore relied on the result of the ict test for pangolin scales. Following the tests for design effects, we calculated the difference in means between the treatment and control unmatched count technique responses to estimate the prevalence of consumption for each product, including the standard error. We compared estimates of prevalence from the unmatched count technique and direct question responses, including confidence intervals and the significance of differences, using the predict.ictreg function.

Lastly, we carried out a multivariate analysis to identify correlates of our best estimates of consumption, using the ict reg test. The variables tested were: district of residence, age, gender, education, income, marital status and profession. We first tested these variables for collinearity using Cramer's V Package for nominal variables. No collinearity was found (at $\geq 0.5$ ) among the demographic variables and they were therefore all included in the same model. Levels in profession, education, income and age levels were combined into relevant categories and used in the model (Supplementary Material 2). The strength of association was determined by whether the standard error of estimates crossed zero; if it did not, the association was considered strong.

\section{Results}

Our best prevalence estimates of consumption for all three pangolin products in the 12 months prior to the survey were $7.1 \pm$ SE $5.7 \%$ (95\% CI: - 4, 18.2\%) for pangolin meat, $10.1 \pm$ SE $5.7 \%$ (95\% CI: $-1.2,21.4 \%)$ for scales, and $6.5 \pm$ SE 6.3 ( $95 \%$ CI: $-5.7,18.8 \%$ ) for wine (Fig. 2). The specialized questioning technique detected a higher prevalence of consumption for meat and scales than the direct questions, which yielded estimates of $0.70 \%$ and $0.08 \%$ respectively, suggesting that consumption of pangolin meat and scales are sensitive behaviours in Ho Chi Minh City. The direct question for pangolin wine consumption elicited a prevalence of $0.50 \%$, overlapping with the standard error of the unmatched count technique prevalence estimate (Fig. 2).

The multivariate analysis provided insights into characteristics of respondents that may affect whether they consume pangolin products (Table 1). Overall, individuals who were more likely to consume pangolin wine have similarities with both consumers of meat and consumers of scales. Consumers of pangolin meat and wine were more likely to work in occupations in service industry, primary production such as farming, and industrial sectors. An age $\leq 55$ years, 


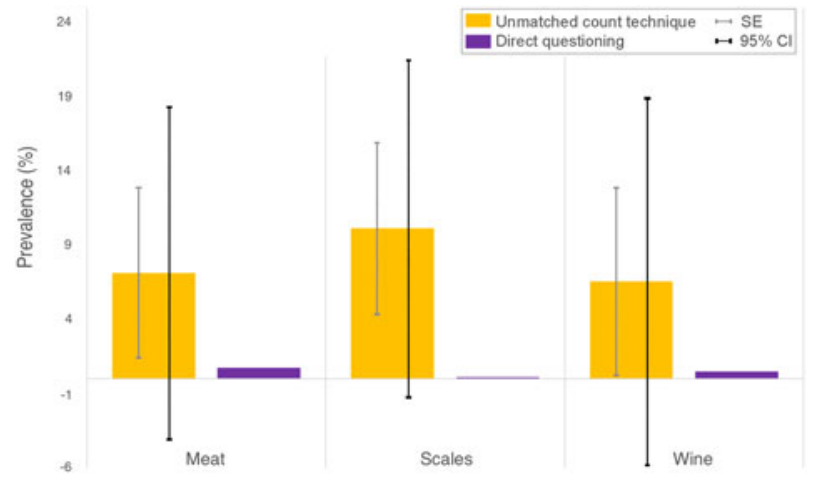

FIG. 2 Estimate of prevalence of consumption (per cent of the sample of respondents) of pangolin meat, scales and wine in Ho Chi Minh City elicited from the unmatched count technique and from direct questioning, with error bars representing the standard error and 95\% confidence interval.

TABLE 1 Summary of ict reg test of demographic variables examined for association with consumption of pangolin meat, scales and wine, with the reference level for each variable (i.e. the level against which other levels were compared). Levels that were significantly different from the reference level are marked with *. Significantly higher and lower consumption of a product compared to the reference level is indicated with + and -, respectively (e.g. residents of Binh Tan district are significantly less likely to consume pangolin wine than residents of District 5, but all the other districts have similar levels of consumption to District 5). The full data are in Supplementary Material 3.

\begin{tabular}{|c|c|c|c|}
\hline Variables & Meat & Scales & Wine \\
\hline \multicolumn{4}{|c|}{ District of residence (reference level: District 5) } \\
\hline \multicolumn{4}{|c|}{ District 6} \\
\hline \multicolumn{4}{|l|}{ Binh Chanh } \\
\hline \multicolumn{3}{|l|}{ Binh $\operatorname{Tan}^{\star}$} & - \\
\hline Nha Be $e^{*}$ & & - & \\
\hline Tan Binh ${ }^{\star}$ & & - & \\
\hline \multicolumn{4}{|c|}{ Age (reference level: $18-25$ years) } \\
\hline \multicolumn{4}{|c|}{$26-35$} \\
\hline \multicolumn{4}{|l|}{$36-55$} \\
\hline$>55^{\star}$ & - & + & \\
\hline \multicolumn{4}{|c|}{ Gender (reference level: women) } \\
\hline \multicolumn{4}{|c|}{ Men } \\
\hline \multicolumn{4}{|c|}{ Education (reference level: basic) } \\
\hline \multicolumn{4}{|c|}{ Very basic } \\
\hline Higher education* & + & & \\
\hline \multicolumn{4}{|c|}{ Income in VND (reference level: low, $\leq 10$ million) } \\
\hline Mid, $10-30$ million $^{*}$ & - & & + \\
\hline \multicolumn{4}{|c|}{ High, $>30$ million } \\
\hline \multicolumn{4}{|c|}{ Marital status (reference level: married) } \\
\hline Single & & & + \\
\hline \multicolumn{4}{|c|}{ Profession (reference level: elementary) } \\
\hline Homemaker* & - & & - \\
\hline Other ${ }^{\star}$ & - & + & - \\
\hline Professional ${ }^{\star}$ & - & & - \\
\hline Retiree $^{\star}$ & - & & - \\
\hline Student ${ }^{\star}$ & - & & - \\
\hline Unemployed ${ }^{*}$ & - & & - \\
\hline
\end{tabular}

lower income and a higher education (college, university and postgraduate) were strongly associated with pangolin meat consumption but not wine or scales. Unmarried individuals and those earning a medium income were more likely to consume pangolin wine. District of residence had a strong association with the consumption of pangolin wine and scales; residents of District 5 were more likely to consume both of these products than residents of other districts. A strong association was found with age and consumption of scales; older individuals ( $>55$ years) and those working in 'other' professions were more likely to consume this product.

\section{Discussion}

Our results corroborate the findings of previous research that consumption of pangolin products occurs in Ho Chi Minh City (Do et al., 2011; ENV, 2016; WildAid, 2016; USAID, 2018). Although the unmatched count technique results have large errors, which is a common drawback of this method (Nuno et al., 2013), the prevalence estimates one standard error below the best estimate (a commonly used approximation for the likely minimum estimate of prevalence) suggest c. $2 \%$ of Ho Chi Minh City's population consume pangolin meat and $4 \%$ consume scales. Given that the city has a population of 8.4 million people, these results suggest that the number of people who may have consumed pangolin meat and scales in the 12 months prior to the survey could be 170,000-340,000. The direct questions also provided positive prevalence estimates, but they were substantially lower than those resulting from the unmatched count technique, especially for scales. Our best estimates for meat consumption are broadly of the same magnitude as previous studies, but our best estimates for scale and wine consumption are substantially higher (Table 2). This could be because other studies did not mitigate response bias; the differences between the responses to the direct and indirect questions suggest that consumption of scales in particular is a sensitive behaviour. Drury et al. (2011) found $<2 \%$ of 915 individuals surveyed in Hanoi admitted to consuming pangolin meat in the previous year; this prevalence is slightly lower than estimates generated by research conducted in Ho Chi Minh City (Table 2). However, Drury et al. (2011) surveyed four central districts, which are unlikely to be representative of the city's population as a whole.

We cannot differentiate our unmatched count technique prevalence estimates from zero at a 95\% level of statistical certainty, as the confidence intervals cross zero for all three products (Fig. 2). Responses to our direct questions indicated positive prevalence, nevertheless, meaning we can be more certain that consumption of pangolin meat, scales and wine occurs in Ho Chi Minh City. Most unmatched count technique studies (e.g. Hinsley et al., 2016; Veríssimo et al., 2020) present estimates with their standard errors (encompassing c. $66 \%$ of the distribution around the best 


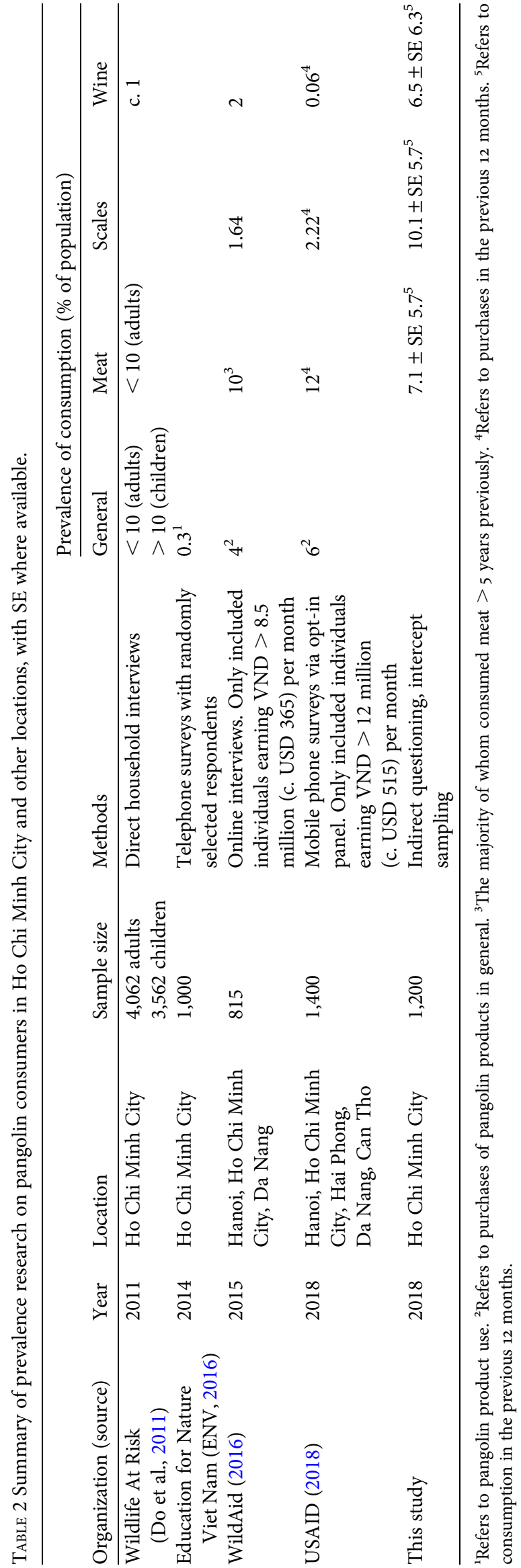

estimate), rather than confidence intervals (encompassing c. $95 \%$ of the distribution around the best estimate). We present both, for consistency with previous studies, and we recommend that future unmatched count technique studies do the same. The wide confidence intervals probably result from the consumption of pangolin products being a sensitive behaviour that has low prevalence. These issues can only be tackled with larger sample sizes and/or more targeting of sampling towards groups with known higher prevalence of the sensitive behaviour. This is, however, a post hoc methodological insight. When investigating sensitive behaviours, an a priori power analysis to calculate sample size can only be done based on what is known about the prevalence of the behaviour. Targeting of particular groups for sampling is more likely to be useful once factors associated with consumption in the general population are understood.

It is possible that the design of our unmatched count technique questions had limitations, despite pre-testing with the target audience. This is most relevant to our estimates of pangolin wine consumption, which had the widest confidence intervals and the lowest prevalence. Levels of consumption of this product require further investigation. The use of other beverages in the control items for pangolin wine in the unmatched count technique question may have aroused suspicion about the sensitive item. Pangolin wine use might be more common as a health tonic, given that previous research indicates pangolin products are perceived to promote good health (USAID, 2018), in which case control items should have been other traditional medicines/tonics rather than beverages not associated with medicinal benefits.

Despite these limitations, our prevalence estimates are currently the best available. Consumers of pangolin scales were mostly $>55$ years old, consistent with previous research indicating that scales, which are used in traditional medicine, are in general used by older people in Viet Nam (Drury, 2011), to treat chronic illnesses (Woerdenbag et al., 2012). Previous research in Viet Nam has also identified mothers as consumers of pangolin scales, as the scales, combined with other ingredients in traditional medicine, are believed to promote lactation (WildAid, 2016; USAID, 2018). However, this has been described as an occasional purchase and of low importance for conservation purposes (USAID, 2018). We did not find a strong association between gender and any of the pangolin products, also suggesting scale consumption to support lactation is not a strong driver of demand. Although rural and urban districts were sampled separately, we found no evidence that consumption differed between district types. The only district in which we detected a higher consumption prevalence was District 5, for scales and wine, which is unsurprising as there are many shops selling traditional medicines in this district (Nguyen et al., 2009). Accessibility of pangolin products might be sufficient to facilitate and encourage consumption, as on Bioko Island, Equatorial Guinea, where 
availability of wild species in markets drove consumption of bushmeat (Fa et al., 2002).

The demographic characteristics strongly associated with pangolin consumption in our study differ from findings of previous research. A study in five cities, including Ho Chi Minh City (USAID, 2018) found pangolin consumers were more likely to be men, with a mean age of 35.8 years and a high income (VND > 23.5 million monthly, c. USD 1,010). Sandalj et al. (2016) identified consumers of wild meat, including of pangolins, in Ho Chi Minh City as wealthy business elites and government officials. Do et al. (2011) described consumers of wildlife products, including pangolins, in Ho Chi Minh City as wealthy middle-aged men. Drury (2011) found businessmen and finance professionals, and those with a high income, were more likely to consume wild meat, including pangolins, than other groups in Hanoi. Our findings suggest men are not more likely to consume pangolin products than women, the youngest age group surveyed (18-25 years old) is more strongly associated with consumption of pangolin meat than older individuals, and lower-earning individuals are more likely to eat pangolin meat than those with a higher income. However, the association between pangolin wine and a medium income suggests this product may be more expensive than the other two products.

Having achieved a higher education is associated with consumption of pangolin meat, as is being younger. This perhaps suggests that recent university graduates are likely to consume this product. These results are similar to those of Sandalj et al. (2016), which indicate that students and individuals with a higher level of education were more likely to be consumers of wild meat than other groups. Unmarried individuals are more likely to consume pangolin wine; we speculate these individuals socialize more than married people. Our results also differ from existing research regarding profession. Those strongly associated with consumption of pangolin meat and wine in our study are individuals with elementary occupations rather than individuals working in managerial, business or high-ranking positions or as government staff (as found by Sandalj et al., 2016; Shairp et al., 2016). However, the differences found between our results and those of Drury (2011) and Sandalj et al. (2016) may be a result of consumer variation between study locations; these studies focused on different Vietnamese cities (Davis et al., 2019b). The similar professional profiles of consumers of pangolin meat and wine suggests they might be obtaining these products from the same sources. Combined with the result that younger, better educated and unmarried people were consumers, this suggests consumption of meat and wine in wild meat restaurants. Overall, our study suggests that the consumers of pangolin meat and wine are more diverse than previously described.

Comparison of our results with previous research requires caution because of fundamental differences in study design (Table 2). Consequently, results from previous studies are not likely to be representative of Ho Chi Minh City's broader population, as they selected respondents representing specific groups. A limiting factor in our study is that only locations with high foot traffic were surveyed in each target district, which will also have created biases (e.g. towards people who are out in public during the day and evenings and those who frequent busier places). Additionally, although we surveyed only Vietnamese nationals, there is a large Chinese community in the city, particularly in District 5. Our anecdotal evidence suggests this community might also be consuming pangolin products.

Our findings have implications for interventions to address consumer demand, and for law enforcement regarding pangolin products in Ho Chi Minh City and more broadly in Viet Nam. Although previous research has identified wealthy, middle-aged men as consumers of several wildlife products (Drury, 2011; Olmedo et al., 2018), this group may not represent the majority of consumers. Further research should focus on understanding the context of consumption of each pangolin product and the underlying motivations of different consumer groups. This could inform the design of targeted behaviour change interventions to address demand, a recognized priority for pangolin conservation (IUCN SSC Pangolin Specialist Group et al., 2018). Various behaviour change strategies to achieve a reduction in the consumption of pangolins have been proposed and could be trialled in Viet Nam (Burgess et al., 2020). Pangolin scales are currently sold openly but illegally in Ho Chi Minh City (Challender et al., 2015), especially in District 5 where consumption of scales and wine appears to be prevalent.

Our study suggests that the unmatched count technique is a useful method for examining illicit and/or sensitive behaviours in conservation, but the technique has limitations. Design and implementation require significant planning and testing, which can be hindered by time and resource constraints (Hinsley et al., 2019; Davis et al., 2019a). The inclusion of an item or behaviour of interest among a list of other items or behaviours generates wider confidence intervals than other methods (Glynn, 2013) such as the ballot box technique (Bova et al., 2018). The unmatched count technique is therefore not the most appropriate method when the behaviour of interest has a very low prevalence and/or when only small sample sizes can be obtained (Ibbet et al., 2017; Davis et al., 2019a). This is an important limitation because the conservation implications of the result depend on both the magnitude of the best estimate and the confidence interval. A low estimated prevalence is not the same as one that cannot be differentiated from zero because the confidence interval is large. This limitation also makes it difficult to use the unmatched count technique longitudinally; e.g. to understand whether there has been a change in the prevalence of a behaviour as a result of an intervention.

To our knowledge, this is the first published study that has used a specialized questioning technique to explore 
consumption of pangolin products. Our findings indicate consumption of pangolin scales, meat, and wine in Ho Chi Minh City. Consumption also takes place in other urban centres, including Hanoi (USAID, 2018) and Hue (Sandalj et al., 2016). The magnitude of the consumption of pangolins in Viet Nam is probably placing pressure on already declining wild pangolin populations in the country (Newton et al., 2008). Our results suggest a large number of pangolin consumers in Ho Chi Minh City alone, indicating the need for urgent conservation action. This consumption is also likely to be putting pressure on populations elsewhere in South-east Asia (Challender et al., 2020) and, regarding scales, in Africa (Heinrich et al., 2016; Ingram et al., 2018). Addressing consumption of pangolin products in Viet Nam, by targeting the prevailing high level of demand and availability of products, is a priority to protect these species.

Acknowledgements We thank our team of Research Assistants in Ho Chi Minh City (Ngọc Phú, Lê Long, Lê Thị Thu Hiền, Lương Thế Dương, Minh Phương, Phạm Ngọc Bích, Võ Trâm and Vũ Loan), and the National Geographic Society and the Oxford Martin Programme on the Illegal Wildlife Trade for financial support.

Author contributions Conceptualization: AO, DV, EJM-G, DC; instrument and sampling design: AO, DV, EJM-G, AH, DC; piloting: AO, DV, AH, DC, HTTD; fieldwork: AO, HTTD; analysis: AO, DV, EJM-G, AH; writing: AO, DV, EJM-G, AH, DC.

\section{Conflicts of interest None.}

Ethical standards This research was approved by the University of Oxford's Social Sciences and Humanities Inter-Divisional Research Ethics Committee (R59702/RE002), adhered to the ethical standards of the Social Research Association, and otherwise abided by the Oryx guidelines on ethical standards. The work was carried out in collaboration with in-country project partner, Save Vietnam's Wildlife, an organization that has permission to conduct social science research in Viet Nam and to hire research assistants.

\section{References}

Aronow, P.M., Coppock, A., Crawford, F.W. \& Green, D.P. (2015) Combining list experiment and direct question estimates of sensitive behaviour prevalence. Journal of Survey Statistics and Methodology, 3, 43-66.

Blair, G., Chou, W., Imai, K., Park, B. \& Coppock, A. (2020) List: Statistical Methods for the Item Count Technique and List Experiment. CRAN Repository. cran.r-project.org/web/packages/ list/list.pdf [accessed 11 February 2021].

Bova, C.S., Aswani, S., Farthing, M.W. \& Potts, W.M. (2018) Limitations of the random response technique and a call to implement the ballot box method for estimating recreational angler compliance using surveys. Fisheries Research, 208, 34-41.

Broad, S., Mulliken, T. \& Roe, D. (2003) The nature and extent of the legal and illegal trade in wildlife. In The Trade in Wildife: Regulation for Conservation (ed. S. Oldfield), pp. 3-22. Taylor \& Francis Group, New York, USA.

Burgess, G., Olmedo, A., Verissimo, D. \& Waterman, C. (2020) Changing consumer behavior for pangolin products. In Pangolins:
Science, Society and Conservation (eds D.W.S. Challender, H.C. Nash \& C. Waterman), pp. 259-282. Academic Press, San Diego, USA and London, UK.

Challender, D.W.S., Harrop, S.R. \& MacMillan, D.C. (2015) Understanding markets to conserve trade-threatened species in CITES. Biological Conservation, 187, 249-259.

Challender, D.W.S. \& MacMillan, D.C. (2014) Poaching is more than an enforcement problem. Conservation Letters, 7, 484-494.

Challender, D.W.S., SAs-Rolfes, M., Ades, G.W.J., Chin, J.S.C., Ching-Min Sun, N., Chong, J.L. et al. (2019) Evaluating the feasibility of pangolin farming and its potential conservation impact. Global Ecology and Conservation, 20, 1-15.

Challender, D.W.S., Shepherd, C.R., Heinrich, S. \& Katsis, L. (2020) International trade and trafficking in pangolins, 1900-2018. In Pangolins: Science, Society and Conservation (eds D.W.S. Challender, H.C. Nash \& C. Waterman), pp. 259-282. Academic Press, San Diego, USA and London, UK.

Chong, J.L., Panjang, E., Willcox, D., Nash, H.C., Semiadi, G., Sodsai, W. et al. (2020) Sunda pangolin Manis javanica (Desmarest, 1822). In Pangolins: Science, Society and Conservation (eds D.W.S. Challender, H.C. Nash \& C. Waterman), pp. 90-108. Academic Press, San Diego, USA and London, UK.

CITES (2016) Res. Conf. 17.4 Demand Reduction Strategies to Combat Illegal Trade in CITES-listed species. cites.org/sites/default/files/ document/E-Res-17-04.pdf [accessed 19 August 2019].

Davis, E.O., Crudge, B., Lim, T., O’Connor, D., Roth, V., Hunt, M. et al. (2019a) Understanding the prevalence of bear part consumption in Cambodia: a comparison of specialised questioning techniques. PLOS ONE, 14, eo214392.

Davis, E.O., Glikman, J.A., Crudge, B., Dang, V., Willemsen, M., NGuYen, T. et al. (2019b) Consumer demand and traditional medicine prescription of bear products in Vietnam. Biological Conservation, 235, 119-127.

Do, H.T.T., Bui, M.H., HoAnG, H.D. \& Do, H.T.H. (2011) Consumption of Wild Animal Products in Ho Chi Minh City, Vietnam-Results of Resident and Student Survey. Wildlife at Risk, Ho Chi Minh City, Viet Nam.

DRURY, R. (2011) Hungry for success: urban consumer demand for wild animal products in Vietnam. Conservation and Society, 9, 247-257.

ENV (Education for Nature Vietnam) (2016) Pangolin Consumer Crime in Vietnam: The Results of ENV Surveys and Enforcement Campaigns, 2011-2015. envietnam.org/images/News_ Resources/Publication/jan-28-2016-pangolin-TCM-survey-results. pdf [accessed 17 September 2019].

ENV (Education for Nature Vietnam) (2017) Stop Pangolin Consumption and Trade. env4wildlife.org [accessed 21 August 2019].

Fa, J.E., Juste, J., Burn, R.W. \& Broad, G. (2002) Bushmeat consumption and preferences of two ethnic groups in Bioko Island, West Africa. Human Ecology, 30, 397-416.

Falkingham, J. \& Namazie, C. (2002) Measuring Health and Poverty: A Review of Approaches to Identifying the Poor. Department for International Development Health Systems Resource Centre, London, UK. assets.publishing.service.gov.uk/media/ 57ao8d46ed915d622coo18bd/Measuring-health-and-poverty.pdf [accessed 25 June 2020].

General Statistics Office (2016) Result of the Viet Nam Household Living Standard Survey. Social and Environmental Statistics Department. Statistical Publishing House, Ho Chi Minh City, Viet Nam.

GLYNN, A.N. (2013) What can we learn with statistical truth serum? Design and analysis of the list experiment. Public Opinion Quarterly, $77,159-172$.

Greenfield, S. \& Veríssimo, D. (2018) To what extent is social marketing used in demand reduction campaigns for illegal wildlife 
products? Insights from elephant ivory and Rhino horn. Social Marketing Quarterly, 25, 40-54.

Hanoi Statement (2016) Hanoi Conference on Illegal Wildlife Trade. 17-18 November 2016, Hanoi, Viet Nam. traffic.org/site/assets/files/ 2808/hanoi-statement-on-illegal-wildlife-trade.pdf [accessed 19 August 2019].

Heinrich, S., Wittmann, T.A., Prowse, T.A.A., Ross, J.V., Delean, S., Shepherd, C.R. \& Cassey, P. (2016) Where did all the pangolins go? International CITES trade in pangolin species. Global Ecology and Conservation, 8, 241-253.

Heinrich, S., Wittman, T.A., Ross, J.V., Shepherd, C.R., Challender, D.W.S. \& CAssey, P. (2017) The Global Trafficking of Pangolins: A Comprehensive Summary of Seizures and Trafficking Routes from 2010-2015. TRAFFIC, Southeast Asia Regional Office, Petaling Jaya, Selangor, Malaysia.

Hinsley, A., Keane, A., St John, F.A.V., Ibbett, H. \& Nuno, A. (2019) Asking sensitive questions using the unmatched count technique: applications and guidelines for conservation. Methods in Ecology and Evolution, 10, 308-319.

Hinsley, A., Nuno, A., Ridout, M., St John, F.A.V. \& Roberts, D.L. (2016) Estimating the extent of CITES noncompliance among traders and end-consumers; lessons from the global orchid trade. Conservation Letters, 10, 602-609.

Ho Chi Minh City S tatistical Office (2016) Ho Chi Minh City Statistical Yearbook. Statistical Publishing House, Ho Chi Minh City, Viet Nam.

Hubbard, M.L., Caspar, R.A. \& Lessler, J.T. (1989) Respondent reactions to item count lists and randomized response. In Proceeding of the American Statistical Association, Section for Survey Research Methods, pp. 544-548. American Statistical Association, Washington, DC, USA.

Ibbet, H., Lay, C., Phlai, P., Song, D., Hong, C., Mahood, S.P. et al. (2017) Conserving a globally threatened species in a semi-natural, agrarian landscape. Oryx, 53, 181-191.

IMAI, K. (2011) Multivariate regression analysis for the item count technique. Journal of American Statistical Association, 106, 407-416.

Ingram, D.J., Coad, L., Abernethy, K.A., Maisels, F., Stokes, E.J., Вово, K.S. et al. (2018) Assessing Africa-wide pangolin exploitation by scaling local data. Conservation Letters, 11, 1-9.

IUCN SSC Pangolin Specialist Group (2016) The Status, Trade and Conservation of Pangolins (Manis spp.) CITES CoP17 Inf., Doc. 59. cites.org/sites/default/files/eng/cop/17/InfDocs/E-CoP17Inf-59.pdf [accessed 19 August 2019].

IUCN SSC Pangolin SPeCialist Group, IUCN SSC Asian Species Action Partnership, Wildlife Reserves Singapore \& IUCN SSC Conservation Planning Specialist Group (2018) Regional Sunda Pangolin (Manis javanica) Conservation Strategy 2018-2028. IUCN SSC Pangolin Specialist Group, Zoological Society of London, London, UK.

Maxwell, S.L., Fuller, R.A., Brooks, T.M. \& Watson, J.E.M. (2016) The ravages of guns, nets and bulldozers. Nature, 536, 143-145.

Newing, H., Eagle, C.M., Puri, R.K. \& Watson, C.W. (2010) Conducting Research in Conservation. Routledge Taylor \& Francis Group, London, UK and New York, USA.

Newton, P., Nguyen, T.V., Roberton, S. \& Bell, D. (2008) Pangolins in peril: using local hunters' knowledge to conserve elusive species in Vietnam. Endangered Species Research, 6, 41-53.

Nguyen, D.X., Ngo, T.X., Pham, P.H. \& Nguyen, N.X. (2009) The Pangolin Trade in Viet Nam. Traffic Southeast Asia, Greater Mekong Programme, Hanoi, Viet Nam.

Nijman, V. (2009) An overview of international wildlife trade from Southeast Asia. Biodiversity Conservation, 19, 1101-1114.

Nuno, A., Bunnefield, N., Naiman, L.C. \& Milner-Gulland, E.J. (2013) A novel approach to assessing the prevalence and drivers of illegal bushmeat hunting in the Serengeti. Conservation Biology, 27, 1355-1365.

Nuno, A. \& S T John, F.A.V. (2015) How to ask sensitive questions in conservation: a review of specialized questioning techniques. Biological Conservation, 189, 5-15.

Olmedo, A., Sharif, V. \& Milner-Gulland, E.J. (2018) Evaluating the design of behavior change interventions: a case study of rhino horn in Vietnam. Conservation Letters, 11, 1-9.

Presser, S. \& Stinson, L. (1998) Data collection mode and social desirability bias in self-reported religious attendance. American Sociological Review, 63, 137-145.

R Core Team (2019) R: A language and environment for statistical computing. R Foundation for Statistical Computing, Vienna, Austria. R-project.org [accessed 12 November 2020].

SAndalj, M., Treydte, A.C. \& Ziegler, S. (2016) Is wild meat luxury? Quantifying wild meat demand and availability in Hue, Vietnam. Biological Conservation, 194, 105-112.

Shairp, R., Veríssimo, D., Fraser, I., Challender, D. \& MacMillan, D. (2016) Understanding urban demand for wild meat in Vietnam: implications for conservation actions. PLOS ONE, 11, e0134787.

St John, F.A.V., Edwards-Jones, G. \& Jones, P.G.J. (2010) Conservation and human behaviour: lessons from social psychology. Wildlife Research, 37, 658-667.

Thomas, J.M., Ursell, A., Robinson, E.L., Aveyard, P., Jebb, S.A., Herman, C.P. \& Higgs, S. (2017) Using a descriptive social norm to increase vegetable selection in workplace restaurant settings. Health Psychology, 36, 1026-1033.

Tourangeau, R., Rips, L.J. \& Rasinski, K. (2000) The Psychology of Survey Response. Cambridge University Press, Cambridge, UK.

Tourangeau, R. \& Yan, T. (2007) Sensitive questions in surveys. Psychological Bulletin, 133, 859-883.

Tsuchiya, T., Hirai, Y. \& OnO, S. (2007) A study of the properties of the item count technique. Public Opinion Quarterly, 71, 253-272.

UNODC (2015) Wildlife and Forest Crime Analytic Toolkit. unodc. org/documents/southeastasiaandpacific/Publications/wildlife/ Vietnam_Toolkit_Report_EN_-_final.pdf [accessed 24 June 2020]. USAID (2018) Research Study on Consumer Demand for Elephant, Rhino and Pangolin Parts and Products in Vietnam. usaidwildlife asia.org/resources/reports/ussv-quant-report-saving-elephantspangolins-and-rhinos-20181105.pdf [accessed 19 August 2019].

Veríssimo, D., Vieira, S., Monteiro, D., Hancock, J. \& Nuno, A. (2020) Audience research as a cornerstone of demand management interventions for illegal wildlife products: demarketing sea turtle meat and eggs. Conservation Science and Practice, 2, 1-14.

Veríssimo, D. \& Wan, A.K.Y. (2018) Characterizing efforts to reduce consumer demand for wildlife products. Conservation Biology, $33,623-633$.

Wild Aid (2016) Pangolins on the Brink. wildaid.org/wp-content/ uploads/2017/o9/WildAid-Pangolins-on-the-Brink.pdf [accessed 19 August 2019].

Wild Aid (2019) New Campaign Urges Vietnamese to Stop Buying Wildlife Products on Eve of Lunar New Year. wildaid.org/newcampaign-urges-vietnamese-to-stop-buying-wildlife-products-oneve-of-lunar-new-year [accessed 21 August 2019].

Woerdenbag, J.H., Nguyen, T.M., Vu, D.V., Nguyen, D.T., Thanh, T.V., S MET, P.D. et al. (2012) Vietnamese traditional medicine from a pharmacist's perspective. Expert Review of Clinical Pharmacology, 5, 459-477.

Wu, S., Sun, N.C., Zhang, F., Yu, Y., Ades, G., Suwal, T.L. et al. (2020) Chinese Pangolin Manis pentadactyla (Linnaeus, 1758). In Pangolins: Science, Society and Conservation (eds D.W.S. Challender, H.C. Nash \& C. Waterman), pp. 50-70. Academic Press, San Diego, USA and London, UK. 